\title{
Socio-cultural factors influencing the prevention of mother-to-child transmission of HIV in Nigeria: a synthesis of the literature
}

\author{
Juliet Iwelunmor ${ }^{* *}$, Echezona E Ezeanolue ${ }^{2}$, Collins $O$ Airhihenbuwa ${ }^{3}$, Michael C Obiefune ${ }^{4}$, Chinenye O Ezeanolue ${ }^{5}$ \\ and Gbenga G Ogedegbe ${ }^{6}$
}

\begin{abstract}
Background: Currently, Nigeria alone accounts for 30\% of the burden of mother-to-child transmission of HIV. This review explores the socio-cultural factors influencing prevention of mother-to-child transmission of HIV (PMTCT) service uptake in Nigeria.

Methods: Using the PEN-3 cultural model as a guide, we searched electronic databases and conducted a synthesis of empirical studies conducted from 2001 to 2013 that reported the perceptions people have towards PMTCT, the enablers/resources that influence PMTCT service uptake, and the role of nurturers/family or community in shaping actions and decisions towards PMTCT service uptake.

Results: A total of 42 articles meeting the search criteria were retained in this review. Thirty-six (36) were quantitative cross-sectional surveys; three were mixed methods, while three were qualitative studies. The findings highlight that there are perceptions, ranging from positive to negative that influence PMTCT service uptake in Nigeria. Furthermore, lack of available, accessible, acceptable, and affordable resources negatively influence decisions and actions towards PMTCT. Finally, family contexts matter with decisions and actions towards PMTCT service uptake in Nigeria particularly with disclosure and non-disclosure of sero-positive status, fertility intentions and infant feeding choices.

Conclusion: As ambitious goals are established and unprecedented resources deployed towards the elimination of mother-to-child transmission of HIV globally by 2015 , there is clearly a need to develop effective family-oriented, culture-centered community-based PMTCT programs in Nigeria so as to improve the low uptake of PMTCT services.
\end{abstract}

Keywords: Socio-cultural factors, PMTCT, PEN-3 cultural model

\section{Background}

HIV infection among women of child-bearing age and mother-to-child transmission (MTCT) of HIV in Nigeria remain major health issues $[1,2]$. The statistics are startling. In 2009, according to the Nigerian National Agency for the Control of AIDS (NACA), about 1.72 million women and girls were living with HIV and AIDS with the highest prevalence rate of $5.6 \%$ among women in the age group 25-29 [3]. In 2012, there were 110,000 new HIV infections among women aged 15-49 years in Nigeria, ranking the

\footnotetext{
* Correspondence: jiwez@illinois.edu

'Department of Kinesiology and Community Health, University of Illinois, Urbana-Champaign, 123 Huff Hall, 1206 S. Fourth St, Champaign, IL 61820, USA

Full list of author information is available at the end of the article
}

country second (next only to South Africa) among countries with the highest burden of new HIV infections among women [4]. Nigeria is one of 22 countries that account for $90 \%$ of pregnant women living with HIV [1]. In 2010, despite improved efforts dedicated to the prevention of mother-to-child HIV transmission (PMTCT), only 16.9\% of pregnant women in Nigeria were tested for HIV [5]. The low rates of testing and treatment in Nigeria contributed to an estimated 75,000 HIV-infected infants in 2010 $[1,6]$. In 2012, while these rates dropped, 60,000 new HIV infections occurred among children, now making Nigeria the country with the largest number of children acquiring HIV through MTCT [4]. Currently, Nigeria alone, "accounts for 30\% of the burden of MTCT" [7]. Without urgent action in Nigeria, UNAIDS suggests that the global 
target of eliminating new HIV infections among children by 2015 is unlikely to be reached [4].

The World Health Organization (WHO) along with key strategic partners is fully committed to the prevention-ofmother-to child transmission of HIV through; primary prevention of HIV infection among women of childbearing age, preventing unintended pregnancies among women living with HIV and scaling up access to effective PMTCT services that prevent HIV transmission from a woman living with HIV to her infant, and provides appropriate treatment, care and support for mothers living with HIV, their children and their families [8]. In addition, effective PMTCT interventions, particularly in resource-poor settings, have the potential to avert pediatric infections and save numerous lives. As a result, current national targets in Nigeria include ensuring that at least $80 \%$ of all pregnant women have access to voluntary counseling and testing, $80 \%$ of all HIV-exposed infants have access to early infant diagnosis services, $80 \%$ of all HIV-positive pregnant women and HIV-exposed infants have access to efficacious ARV's and $80 \%$ of HIV-positive pregnant women have access to infant feeding counseling by 2015 [9]. If these targets are to be met by 2015, identifying the socio-cultural factors that influence pregnancy, labor, delivery or breast-feeing are important for the success of PMTCT efforts in Nigeria. Moreover, since culture plays a vital role in determining the level of health of the individual, family, and community [10], it is plausible that knowledge of socio-cultural factors may facilitate efforts aimed at effective PMTCT in Nigeria. This in turn, may reduce missed opportunities including late initiation of prenatal care, low perceptions of risk, failure to disclose knowledge of HIV sero-positive status, and lack of knowledge of the effectiveness of interventions for PMTCT.

Using a cultural model as a guide, this paper reviews the current information available on the socio-cultural factors that influence PMTCT in Nigeria. The implications are discussed in light of ambitious goals and unprecedented resources currently in place to virtually eliminate mother-to-child transmission of HIV by 2015 . Interventions focused on addressing the influence of socio-cultural factors with PMTCT efforts in Nigeria are also discussed.

\section{Theoretical framework: the PEN-3 cultural model}

Developed by Airhihenbuwa, the PEN-3 cultural model addresses the role of culture in the adoption or nonadoption of health behaviors [10,11]. It consists of three domains (see Figure 1); Cultural Identity, Relationships and Expectations, and Cultural Empowerment, that offer the opportunity to centralize culture in the development of health promotion interventions [10]. Each domain includes three factors that form the acronym PEN; Person, Extended Family, Neighborhood (Cultural Identity domain); Perceptions, Enablers, and Nurturers (Relationship

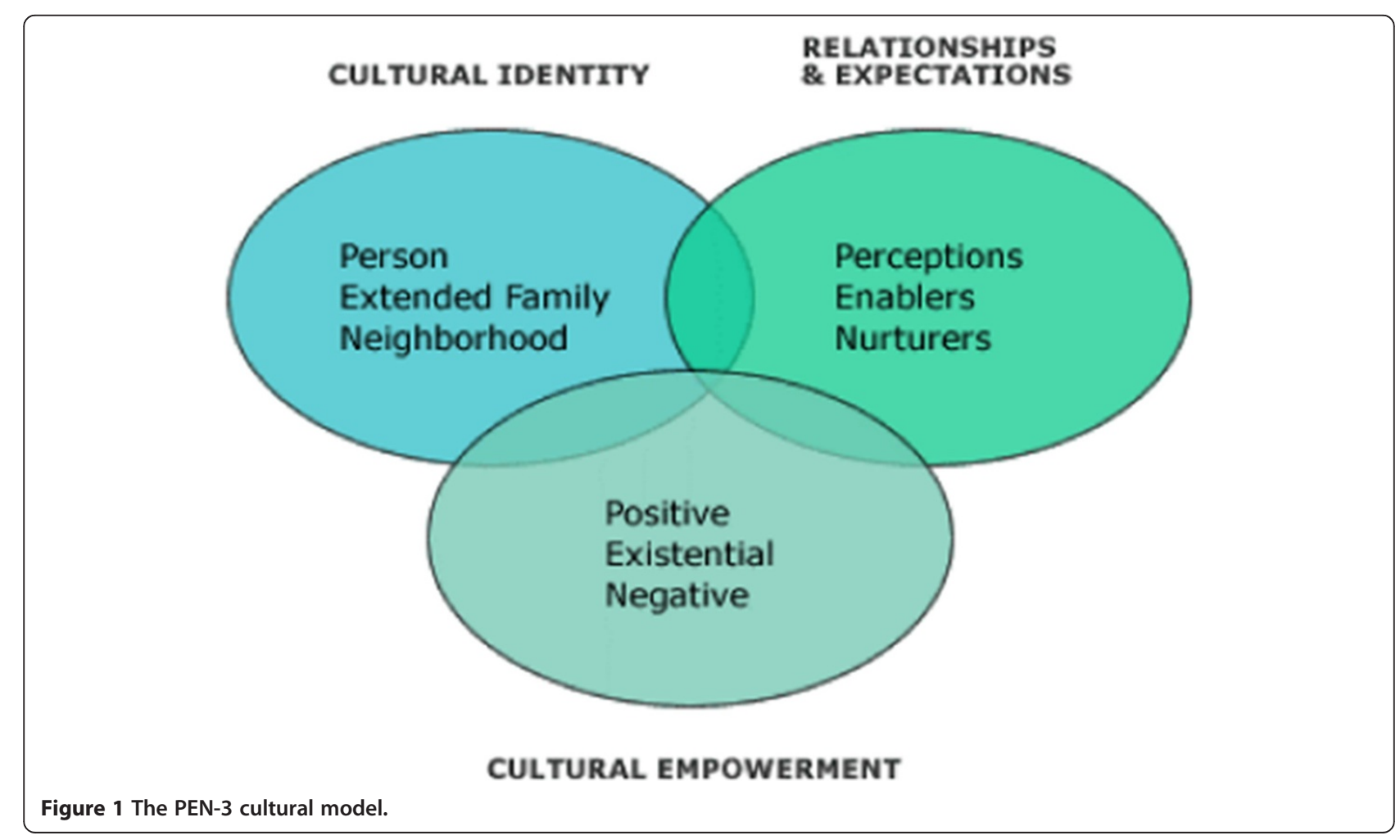


and Expectation domain); Positive, Existential and Negative (Cultural Empowerment domain).

The PEN-3 cultural model also serves as a tool for examining the context that shapes the health behavior of interest. This is achieved by highlighting culturally relevant factors that are influential and should be considered in the development of effective targeted health interventions [12]. Since its inception in 1989, the PEN-3 cultural model has been used to develop effective outreach cancer control interventions for Latinos [12,13], diabetes prevention interventions for African Americans [14], culturally competent domestic violence interventions and preventive services for Chinese immigrants [15], and to conduct community based research on HIV Stigma in South Africa [16]. In this paper, we will focus on the Relationship and Expectations domain as well as the Cultural Empowerment domain of the PEN-3 model. With the Relationships and Expectations domain, findings from the literature will be categorized into Perceptions or attitudes about PMTCT, Enablers or societal/ structural resources such as health care services that promote or discourage effective health seeking practices for PMTCT, and Nurturers such as the influence of family and kin in nurturing decisions surrounding effective participation in PMTCT programs are examined. Findings from the literature will also be categorized based on the Cultural Empowerment domain as either Positive, Existential (unique) or Negative. With the Cultural Empowerment domain, Positive refers to key values that promote PMTCT service uptake; Existential are unique values practiced in the culture that pose no threat to PMTCT service uptake; while Negative includes health beliefs and actions that are harmful and negatively influence decisions or actions to obtain PMTCT services or create barriers to service uptake. Overall, using the PEN3 cultural model as a guide provides the opportunity to identify socio-cultural perceptions, enablers, or nurturers that are positive, acknowledges the ones that are existential, before identifying the negative. In this way, effective culture-centered intervention for PMTCT is as much about promoting these positive values as it is changing negatives ones.

\section{Methods}

We reviewed all published abstracts and journal articles from 2001 to 2013 conducted in Nigeria. The year 2001 was chosen as it was the year the Federal Government of Nigeria adopted the UNGASS (United Nations General Assembly Special Session) goal of reducing the proportion of infants infected with HIV by $20 \%$ by 2005 and $50 \%$ by 2010," as well as increasing universal access to quality voluntary counseling and testing by $50 \%$ by 2010 . A comprehensive search of 5 electronic database; Embase, Google Scholar, JSTOR, PubMed and Sociologic Abstracts were utilized in this review. The review methodology was also adapted from other reviews on PMTCT in sub-Saharan Africa so as to ensure the strength of the assessment [17]. The search terms used for this review contained keywords or texts within a matrix of relevant terminology (e.g. PMTCT + Nigeria, HIV testing + Pregnant Women + Nigeria etc.). Reference list of relevant articles were also searched to identify available literature. The abstracts of all of the documents were initially screened by one reviewer; however, the full-text documents were retrieved and rescreened by two reviewers independently. To be eligible for this review, the article must have included data on socio-cultural factors influencing PMTCT. Specifically, the article must have identified perceptions people may have towards PMTCT, the resources and/or barriers that influence PMTCT service uptake and the role of family or community factors in shaping decisions surrounding participation in PMTCT programs. The study must have also been conducted in Nigeria. The synthesis of the data extracted from the available literature was also conducted using the PEN-3 cultural model as a guide. Also, the quality of included papers were assessed using the standard checklist for assessing the quality of research papers [18]. Specifically, we assessed whether the objectives of the paper where sufficiently described, whether study design was evident and appropriate, whether information on target population was provided, whether data collection methods and analysis were clearly described, whether results were reported in a sufficient manner and whether the conclusion were supported by the results [18]. The searches yielded studies that varied greatly in terms of their sample size, study design, and objectives (see Table 1). Also, PRISMA flow diagram of the literature reviewed is presented in Figure 2.

\section{Results}

Forty-two quantitative, mixed-methods and qualitative papers published between 2001 and 2013 from urban, semi-urban, and rural areas of Nigeria which met our inclusion criteria were included in the synthesis.

Thirty-six (36) were quantitative cross-sectional surveys; three were mixed methods, while three were qualitative studies. Majority involved women, particularly HIV positive women attending ante-natal clinics throughout Nigeria. The initial screening characterized the data into the Relationship and Expectations domain and/or the Cultural Empowerment Domain. The emerging themes were then re-organized by cross-tabulating the Relationship/ Expectations domain with the Cultural Empowerment domain (see Table 2). This approach, known as the assessment phase of the PEN-3 model, provide the opportunity to arrange the emerging themes into perceptions, enabling factors and nurturing factors influencing PMTCT in Nigeria. 
Table 1 Summary of Literature Reviewed

\begin{tabular}{|c|c|c|c|c|}
\hline Reference & $\begin{array}{l}\text { Setting } \\
\text { (Urban/Rural) }\end{array}$ & Sample & Study Type & Aim \\
\hline Nwakwuo et al., 2013 [19] & Semi-Urban & 400 households & Cross-sectional survey & $\begin{array}{l}\text { To assess the level of male involvement } \\
\text { in their spouses' reproductive health } \\
\text { events before pregnancy, during pregnancy, } \\
\text { delivery and peuperium }\end{array}$ \\
\hline Ogbolu et al., 2013 [20] & Rural/Urban & 231 nurses & Cross-sectional survey & $\begin{array}{l}\text { To examine current PMTCT practices in } 27 \\
\text { public health facilities in Nigeria. }\end{array}$ \\
\hline Olugbenga-Bello et al., 2013 [21] & Urban & $\begin{array}{l}420 \text { women } \\
\text { (15-49 years) }\end{array}$ & Cross-sectional survey & $\begin{array}{l}\text { To assess knowledge and attitude of women } \\
\text { of child-bearing age towards PMTCT }\end{array}$ \\
\hline Amoran et al., 2012 [22] & Urban & 225 pregnant women & Cross-sectional survey & $\begin{array}{l}\text { To assess factors associated with the } \\
\text { knowledge and utilization of PMTCT } \\
\text { services by the teenage pregnant } \\
\text { women when compared to mature } \\
\text { pregnant women. }\end{array}$ \\
\hline Hembah-Hilekaan et al., 2012 [23] & Semi-Urban & 384 women & Cross-sectional survey & $\begin{array}{l}\text { To assess knowledge, attitudes and } \\
\text { barriers to the uptake of PMTCT }\end{array}$ \\
\hline Nwabueze et al., 2012 [24] & Semi-Urban & 288 women & Cross-sectional survey & $\begin{array}{l}\text { To assess the determinants of subjective } \\
\text { health status of HIV-positive mothers } \\
\text { assessing PMTCT services }\end{array}$ \\
\hline Ogbe et al., 2012 [25] & Urban & 140 women & Cross-sectional survey & $\begin{array}{l}\text { To determine the contraceptive awareness } \\
\text { among HIV positive women }\end{array}$ \\
\hline Sofolahan et al., 2012 [26] & Urban & 60 women & In-depth interviews & $\begin{array}{l}\text { To understand the factors responsible } \\
\text { for the childbearing decisions of } \\
\text { women living with HIV/AIDS }\end{array}$ \\
\hline Ugwu et al., 2012 [27] & Urban & 150 antenatal clients & Cross-sectional survey & $\begin{array}{l}\text { To study the impact of health education on } \\
\text { the awareness of strategies for PMTCT }\end{array}$ \\
\hline Bello et al., 2011 [28] & Urban & 104 women & Cross-sectional survey & $\begin{array}{l}\text { To assess the acceptability and suitability } \\
\text { of offering HIV counselling and testing to } \\
\text { women of unknown HIV status presenting } \\
\text { in labour. }\end{array}$ \\
\hline Ezegwui et al., 2011 [29] & Urban & $\begin{array}{l}96 \text { HIV positive } \\
\text { pregnant women }\end{array}$ & Cross-sectional survey & $\begin{array}{l}\text { To evaluate sexual behavior and } \\
\text { activity in HIV positive pregnant women } \\
\text { and their sources of information }\end{array}$ \\
\hline Ezeanochie et al., 2011 [30] & Urban & 305 HIV positive women & Cross-sectional survey & $\begin{array}{l}\text { To evaluate the prevalence and correlates } \\
\text { of intimate partner violence among } \\
\text { HIV-positive pregnant Nigerian women. }\end{array}$ \\
\hline Olagbuji et al., 2011 [31] & Urban & 166 HIV positive women & Cross-sectional survey & $\begin{array}{l}\text { To determine the prevalence, pattern and } \\
\text { determinants of spousal disclosure of } \\
\text { HIV serostatus }\end{array}$ \\
\hline Balogun et al., 2010 [32] & Urban & $\begin{array}{l}108 \text { Traditional } \\
\text { Birth Attendants }\end{array}$ & Cross-sectional survey & $\begin{array}{l}\text { To assess the knowledge and practice of } \\
\text { PMTCT amongst TBAs in Lagos, Nigeria. }\end{array}$ \\
\hline Enwereji et al., 2010 [33] & Semi-Urban & $\begin{array}{l}96 \text { PLWHA and } 45 \\
\text { healthcare workers }\end{array}$ & Mixed-method & $\begin{array}{l}\text { To identify factors and conditions that } \\
\text { determine childbirth choices of PLWHA }\end{array}$ \\
\hline Oladokun et al., 2010 [34] & Urban & $\begin{array}{l}51952 \text { women at } \\
\text { antenatal clinic }\end{array}$ & Cross-sectional survey & $\begin{array}{l}\text { To evaluate the service uptake and performance } \\
\text { of PMTCT program using national key indicators }\end{array}$ \\
\hline Oladokun et al., 2010 [35] & Urban & 241 women & Cross-sectional survey & $\begin{array}{l}\text { To evaluate the infant-feeding choices, practices } \\
\text { and possible determinants among HIV-positive } \\
\text { women enrolled in a PMTCT program }\end{array}$ \\
\hline Adeleke et al., 2009 [36] & Urban & 164 mothers & Cross-sectional survey & $\begin{array}{l}\text { To evaluate the awareness and knowledge } \\
\text { of mother-to-child transmission of HIV, } \\
\text { HIV/AIDS and the methods to prevent } \\
\text { mother-to-child transmission of HIV. }\end{array}$ \\
\hline Brown et al., 2009 [37] & Urban & 513 mothers & Cross-sectional survey & $\begin{array}{l}\text { To evaluate breastfeeding and weaning } \\
\text { practices associated socio-demographic } \\
\text { factors and knowledge about mother-to-child } \\
\text { transmission of HIV among mothers }\end{array}$ \\
\hline
\end{tabular}


Table 1 Summary of Literature Reviewed (Continued)

\begin{tabular}{|c|c|c|c|c|}
\hline Ezechi et al., 2009 [38] & Urban & $\begin{array}{l}652 \text { HIV positive } \\
\text { pregnant women }\end{array}$ & Cross-sectional survey & $\begin{array}{l}\text { To determine the prevalence, types and } \\
\text { correlates of intimate partner violence (IPV) } \\
\text { in pregnant Nigerian living with HIV. }\end{array}$ \\
\hline Ezegwui et al., 2009 [39] & Urban & 92 pregnant women & Cross-sectional survey & $\begin{array}{l}\text { To assess HIV serostatus disclosure } \\
\text { pattern among pregnant women }\end{array}$ \\
\hline Maru et al., 2009 [40] & Urban & 469 women & Mixed-methods & $\begin{array}{l}\text { To identify the social determinants } \\
\text { of mixed feeding }\end{array}$ \\
\hline Moses et al., 2009 [41] & Urban & 172 women & Cross-sectional survey & $\begin{array}{l}\text { To determine the level of knowledge, } \\
\text { practice and attitude toward HIV/AIDS } \\
\text { issues with respect to PMTCT }\end{array}$ \\
\hline Mukhtar-Yola et al., 2009 [42] & Urban & 190 HIV exposed babies & Cross-sectional survey & $\begin{array}{l}\text { To determine the sociodemographic } \\
\text { characteristics, infant feeding choices } \\
\text { and outcome of HIV exposed neonates }\end{array}$ \\
\hline Omuemu et al., 2008 [43] & Urban & 200 pregnant women & Cross-sectional survey & $\begin{array}{l}\text { To assess the awareness, attitude } \\
\text { and practice of HIV testing among } \\
\text { antenatal clients }\end{array}$ \\
\hline Onah et al., 2008 [44] & Urban & 635 pregnant women & Cross-sectional survey & $\begin{array}{l}\text { To assess voluntary counselling and } \\
\text { testing }(V C T) \text { uptake, nevirapine use } \\
\text { and infant feeding options among } \\
\text { pregnant women }\end{array}$ \\
\hline Sadoh et al., 2008 [45] & Urban & 103 mothers & Cross-sectional survey & $\begin{array}{l}\text { To evaluate the feeding practices of } \\
\text { HIV-infected mothers in the first six } \\
\text { months of their infants' lives }\end{array}$ \\
\hline Arulogun et al., 2007 [46] & Urban & $\begin{array}{l}20 \text { community } \\
\text { gatekeepers }\end{array}$ & In-depth interviews & $\begin{array}{l}\text { To identify level of awareness } \\
\text { and knowledge of PMTCT services }\end{array}$ \\
\hline Okonkwo et al., 2007 [47] & Semi-Urban & 240 pregnant women & Cross-Sectional Survey & $\begin{array}{l}\text { To determine the awareness, attitudes, } \\
\text { and beliefs of pregnant Nigerian women } \\
\text { toward voluntary counseling and testing } \\
\text { (VCT) for HIV }\end{array}$ \\
\hline Adeneye et al., 2006 [48] & Urban & $\begin{array}{l}804 \text { women at } \\
\text { antenatal clinic }\end{array}$ & Mixed methods & $\begin{array}{l}\text { To assess willingness to seek and undergo } \\
\text { HIV counseling and testing. }\end{array}$ \\
\hline Daniel et al., 2006 [49] & Urban & 333 pregnant women & Cross-sectional survey & $\begin{array}{l}\text { To assess the acceptability of prenatal } \\
\text { HIV screening }\end{array}$ \\
\hline Ekabua et al., 2006 [50] & Urban & $\begin{array}{l}400 \text { women at } \\
\text { antenatal clinic }\end{array}$ & Cross-sectional survey & $\begin{array}{l}\text { To determine the level of awareness, attitude } \\
\text { and practice of antenatal HIV screening }\end{array}$ \\
\hline Sagay et al., 2006 [51] & Urban & 570 HIV positive mothers & Cross-sectional survey & $\begin{array}{l}\text { To explore the issues concerning disclosure of } \\
\text { HIV status to partners of HIV sero-positive } \\
\text { mothers in a PMTCT programme }\end{array}$ \\
\hline Sagay et al., 2006 [52] & Urban & $\begin{array}{l}500 \text { partners } \\
\text { of HIV infected } \\
\text { pregnant women }\end{array}$ & Cross-sectional survey & $\begin{array}{l}\text { To determine the pattern of HIV sero-status of } \\
\text { Partners of HIV Positive Pregnant Women }\end{array}$ \\
\hline Igwegbe et al., 2005 [53] & Semi-Urban & $\begin{array}{l}312 \text { pregnant } \\
\text { women at } \\
\text { antenatal clinic }\end{array}$ & Cross-sectional survey & $\begin{array}{l}\text { To evaluate the knowledge and perceptions of } \\
\text { HIV/AIDS and mother to child transmission } \\
\text { among pregnant women }\end{array}$ \\
\hline Iliyasu et al., 2005 [54] & Urban & $\begin{array}{l}210 \text { women at } \\
\text { antenatal clinic }\end{array}$ & Cross-sectional survey & $\begin{array}{l}\text { To assess pregnant women's knowledge of } \\
\text { HIV/AIDS, awareness and attitudes towards } \\
\text { Voluntary Counselling and Testing (VCT) } \\
\text { in a teaching hospital in northern Nigeria. }\end{array}$ \\
\hline Oladapo et al., 2005 [55] & Semi-Urban & $\begin{array}{l}147 \text { HIV positive } \\
\text { men and women }\end{array}$ & Cross-sectional survey & $\begin{array}{l}\text { To determine the extent of fertility desires } \\
\text { and intentions of HIV-positive patients }\end{array}$ \\
\hline Chama et al., 2004 [56] & Urban & $\begin{array}{l}262 \text { pregnant } \\
\text { women at } \\
\text { antenatal clinic }\end{array}$ & Cross-sectional survey & $\begin{array}{l}\text { To determine uptake of PMTCT services } \\
\text { at an antenatal clinic }\end{array}$ \\
\hline Ekanem et al., 2004 [57] & Urban & $\begin{array}{l}345 \text { pregnant } \\
\text { women at } \\
\text { antenatal clinic }\end{array}$ & Cross-sectional survey & $\begin{array}{l}\text { To determine their knowledge } \\
\text { and acceptability of HIV voluntary } \\
\text { counselling and testing in pregnancy }\end{array}$ \\
\hline
\end{tabular}


Table 1 Summary of Literature Reviewed (Continued)

\begin{tabular}{|c|c|c|c|c|}
\hline Fasubaa et al., 2001 [58] & Semi-Urban & $\begin{array}{l}586 \text { pregnant } \\
\text { women at } \\
\text { antenatal clinic }\end{array}$ & Cross-sectional Survey & $\begin{array}{l}\text { To assess pregnant clients' opinions on the } \\
\text { issue of antenatal HIV screening }\end{array}$ \\
\hline Orji et al., 2001 [59] & Semi-Urban & $\begin{array}{l}200 \text { pregnant } \\
\text { women at } \\
\text { antenatal clinic }\end{array}$ & Cross-sectional survey & $\begin{array}{l}\text { To determine the attitude of pregnant } \\
\text { women to routine HIV screening }\end{array}$ \\
\hline Owolabi et al., 2001 [60] & Semi-Urban & $\begin{array}{l}4 \text { HIV positive } \\
\text { pregnant women }\end{array}$ & Case-Study & $\begin{array}{l}\text { To highlight the socio-economic } \\
\text { implications and the burden of HIV } \\
\text { on maternal and child health }\end{array}$ \\
\hline
\end{tabular}

\section{Perceptions towards PMTCT in Nigeria}

In this paper, perceptions include positive, existential and/or negative knowledge, attitudes, and beliefs that influence decisions and actions towards PMTCT in Nigeria. Table 2 highlights the perceptions identified from the studies reviewed. There was a high level of acceptance with HIV testing, with some participants suggesting 'that pregnant woman should be tested for HIV' [21,22] coupled with a 'willingness to go for voluntary counseling and testing $(V C T)$ ' $[48,57]$. These positive perceptions appeared to be influenced by an increased awareness that 'VCT could reduce the risk of transmission of HIV to babies' [47], as well as by 'increasing educational level, not fearing a blood test; perception that clinics offered privacy; and perceptions of higher levels of social support from relatives and peers'
[48]. Unique or existential perceptions reflect values or beliefs that help to explain practices in the Nigerian culture and could influence attitudes towards PMTCT. In the literature reviewed, 'the desire to have children' was a common existential perception shared by many HIV positive men and women in Nigeria [26,33,61]. Culture, particularly the strong cultural attachment to having children, appeared to influence this desire for childbearing among HIV positive men and women. For example, in a study on the reproductive intent of HIV positive men and women in southeastern Nigeria, the authors found that 'broadly held social expectations with regard to reproduction are experienced even more acutely by HIV-positive people' [62]. Another study found that women with non-formal education were more likely to desire having children than

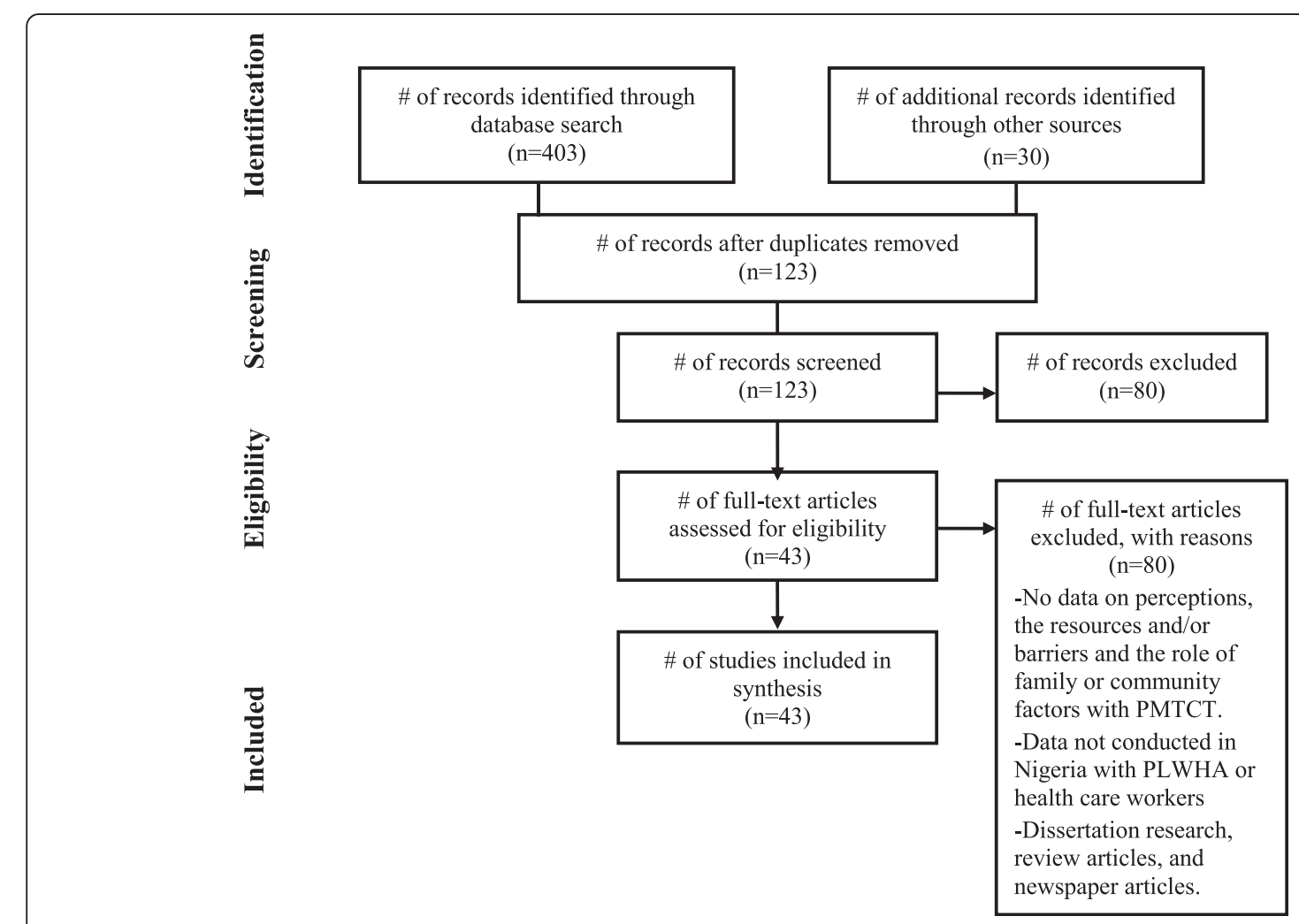

Figure 2 PRISMA flow diagram of literature reviewed. 
Table 2 Themes identified using the PEN-3 cultural model

\begin{tabular}{|c|c|c|c|c|}
\hline & Themes from the literature reviewed & Positive & Existential & Negative \\
\hline \multirow[t]{10}{*}{ Perceptions } & Knowledge of HIV transmission & $x$ & & \\
\hline & Acceptance of VCT & $x$ & & \\
\hline & Willingness to go for VCT & $x$ & & \\
\hline & Desire to have children & & $x$ & \\
\hline & Desire to breastfeed & & $x$ & \\
\hline & Poor condom use knowledge & & & $x$ \\
\hline & Poor awareness of ARV's & & & $x$ \\
\hline & Poor awareness of PMTCT & & & $x$ \\
\hline & Stigma and discrimination & & & $x$ \\
\hline & HIV = death, abandonment, rejection & & & $x$ \\
\hline \multirow[t]{13}{*}{ Enablers } & Confidentiality of HIV test results & $x$ & & \\
\hline & PMTCT Health education programs & $x$ & & \\
\hline & Family planning services, HAART & $x$ & & \\
\hline & Support group and counseling & $x$ & & \\
\hline & Support group and antiretroviral therapy & $x$ & & \\
\hline & Traditional Birth Attendant & & $x$ & \\
\hline & Inadequate VCT and PMTCT centers & & & \\
\hline & Long distance, long waiting times & & & $x$ \\
\hline & Financial difficulties and cost & & & $x$ \\
\hline & Stigma & & & $x$ \\
\hline & Discrimination from health workers & & & $x$ \\
\hline & Lack of confidentiality of results & & & $x$ \\
\hline & Refusal of HIV testing & & & $x$ \\
\hline \multirow[t]{9}{*}{ Nurturers } & Disclosure of status and support & $x$ & & \\
\hline & Male support and involvement & $x$ & & \\
\hline & Family support and infant feeding choice & $x$ & & \\
\hline & Family support and ARV adherence & $x$ & & \\
\hline & Ensure lineage continuity and posterity & & $x$ & \\
\hline & Non-disclosure of seropositive status & & & $x$ \\
\hline & Desire not to procreate & & & $x$ \\
\hline & Stigma & & & $x$ \\
\hline & Family pressure to breastfeed & & & $x$ \\
\hline
\end{tabular}

women with tertiary education [61]. Similarly, the desire to breastfeed was a common existential perception shared by HIV positive women in some studies. One study found that irrespective of HIV status, some women reported that they would still breastfeed their children [57]. Nevertheless, in the literature reviewed, lack of knowledge on condom use [22], the purpose of ARV despite awareness of it $[33,57]$ as well as poor knowledge with regards to PMTCT $[46,48,57]$ were among the major negative perceptions identified. For example, in a study conducted among pregnant women in Western Nigeria, the authors found that participants 'did not know how to correctly use condom to prevent pregnancy and HIV/AIDS infection' [22]. In southeastern Nigeria, one study found a significant number of HIV positive women who discontinued use of iron tablets and/or ARV drugs because they feared it may lead to 'big babies' and 'threatened abortion' [33]. Among participants in southwestern Nigeria, some believed that termination of pregnancy could be a method of preventing mother-to-child transmission of HIV [21]. In determining patterns and determinants of ARV's during pregnancy, researchers [63] found that perceptions of stigma and discrimination such as the fear of being identified as HIV positive' was the most common reason given for nonadherence. Perceptions of stigma and discrimination were frequently observed in majority of the studies reviewed 
with researchers suggesting these are also deterrents to VCT for some pregnant women $[33,47,63]$. Other negative perceptions identified in the literature were the synonymous linking of HIV with death, abandonment and rejection [33].

\section{Enabling factors influencing PMTCT in Nigeria}

In the literature reviewed, enablers refer to the availability, accessibility, acceptability, and affordability of resources that either facilitate or hinder decisions and actions towards PMTCT. For example, confidentiality of HIV test results, availability of health education programs surrounding PMTCT and access to family planning services, HAART, support groups, and counseling services for HIV positive women were some of the positive enablers identified in the literature [64]. In an evaluation of pregnant women's attitudes towards VCT in Awka, Nigeria, the authors found that assurance of confidentiality of results influenced willingness to test for HIV [47]. Also, in Enugu, Nigeria, researchers found a positive and significant impact of health education on the awareness and acceptability of strategies for PMTCT [27]. Another study suggested that establishment of a community peer support group for all nursing mothers (to prevent stigmatization) may assist in changing community norms and beliefs while providing support for HIV positive mothers, especially young mothers who choose to exclusively breastfeed their children [65]. While, early initiation of PMTCT interventions, including the access to more ['counseling sessions during the beginning of pregnancy provided enabling environments for mothers to carry out their infant feeding intentions [65].

Some enablers identified in the literature are also existential, in that they are traditionally available in the community or society and support uptake of PMTCT services. For example, some women living with HIV and AIDS utilized the services of traditional birth attendants before, during, and after pregnancy [32]. Throughout Nigeria, irrespective of HIV status, about $60 \%$ of childbirths are performed by traditional birth attendants [20,32]. Among HIV positive pregnant women, some of the reasons given for assessing the services of traditional birth attendants include the unfriendly attitudes of healthcare workers and the cost of childbirth. Also, since the experience of childbirth is governed by numerous traditional birthing practices, traditional birth attendants were preferred because they provide important information on the local customs, traditions, and perceptions regarding childbirth and new-born care. Balogun and Odeyemi suggest that 'both rural and urban women seek care with traditional birth attendants because they have similar cultural and socio-economic characteristics' [32].
Nevertheless, lack of available, accessible, acceptable, and affordable resources negatively influence decisions and actions towards PMTCT. For example, across the studies reviewed, inadequate and inaccessible voluntary and counseling centers, coupled with long distance to the centers and long waiting lines acted as barriers to PMTCT service uptake. In a study conducted in the Aminu Kano Teaching Hospital in Kano in which the records of HIV positive infants were reviewed, the authors found that inaccessibility to PMTCT centers were among the reasons their mother gave for non-participation in PMTCT program [66]. Further financial difficulties and cost, particularly costs associated with childbirth influenced decisions to participate in PMTCT services at health clinics. This was the case in southeastern Nigeria where researchers observed that high treatment costs influenced the childbirth choices of HIV positive pregnant women [33]. Also, stigma and discrimination from nurses, including non-acceptance, unfriendly attitudes and lack of confidentiality were deterrents in the non-utilization of hospital services $[33,66]$.

\section{Nurturing factors influencing PMTCT in Nigeria}

In the literature reviewed, nurturers refer to the influence of family and/or community contexts in positively or negatively shaping decisions and actions towards PMTCT service uptake in Nigeria. Indeed, disclosure of sero-positive status and subsequent support from family members defined some of the positive nurturers' category. These findings are consistent with studies conducted elsewhere which suggests that family and community systems remain the first and best line of support for caring and supporting family members who are living with HIV and AIDS [67]. In Northern Nigeria, one study observed supportive reactions to HIV sero-positive status among partners of HIV positive women [52]. This was also the case in Enugu, where another study observed a high level of sero-status disclosure of HIV status, with most women disclosing to their partners, and receiving support [39]. Family support which is important in PMTCT programmes also provided optimal access to preventive strategies such as adherence to ARV therapy. For example, in Lagos, disclosure of HIV status and subsequent treatment support from partners was reported to influence the level of adherence to ARVs among pregnant women [63]. Disclosure of sero-positive status to partners also influenced the choice and maintenance of infant feeding $[35,40]$.

In addition to these positive nurturing factors, the literature reviewed revealed certain traditional values and practices influenced by family contexts that shape PMTCT decisions or health-seeking behaviors. For example, with the widespread use of ARV's for the treatment of HIV, as indicated earlier, 'the desire to have children' 
has become a common existential perception shared by many HIV positive men and women living in Nigeria. Participants in some studies reported that the main reasons for wanting to procreate included ensuring lineage continuity and posterity $[26,33,61]$. These desires seemed to be influenced by a strong cultural attachment placed on having children, coupled with the stigma associated with childlessness, role of children in inheritance, importance of children in agricultural economies, importance of childbearing on the status of women and the role of children as caretakers of the elderly [61].

Nevertheless, there were factors influenced by family contexts that negatively shaped decisions and actions towards PMTCT. For example, while some participants willingly disclosed knowledge of their sero-positive status to their partners, in some studies, researchers also observed non-disclosure of sero-positive status. In southeastern Nigeria, one study observed that the fear of divorce, alongside being single, low educational status, Anglican Christian denomination and nonmembership in a support group significantly increased the likelihood of non-disclosure of sero-positive status [68]. Similarly, among HIV positive mothers in Benin City Nigeria, three common reasons given for nondisclosure was 'fear, regarding the spread of the information, stigma and deterioration in the relationship with the spouse' [31]. Non-disclosure of sero-positive status also influenced non adherence to ARV's among HIVpositive pregnant women in Nnewi Nigeria [69]. Among women who disclosed their HIV status, partner testing was found to be dismal in many cases. In an evaluation of PMTCT service uptake among 2152 HIV positive women attending a PMTCT programme in Ibadan, Nigeria, only about $16 \%$ of their partners accepted HIV testing [34]. Also, while there was evidence for a strong desire to procreate given the strong cultural attachment to having children in Nigeria, findings from the literature reviewed also indicated that knowledge of sero-positive status in some cases, influenced decisions not to reproduce. For example, in a study conducted among HIV positive men and women in the Niger Delta Region, the authors found that decisions not to have more children were linked to the fear of infecting a sero-discordant partner and baby, fear of dying and leaving behind orphans, and fear that they may become too ill and unable to support the child financially [61]. For new HIV positive mothers, stigma and family pressure to breastfeed influenced mixed feeding patterns. One study observed that family members input with regards to culturally and socially accepted feeding methods, alongside poor access to proper feeding counseling support influenced high rate of mixed feeding practices in a cohort of HIV positive mothers in the south-south region of Nigeria [70].

\section{Discussion}

There are nearly 1.72 million women and girls living with HIV in Nigeria and the prevalence continues to increase despite efforts by the Nigerian Ministry of Health [3]. Furthermore, 60,000 new HIV infections occurred among children, making Nigeria the country with the largest number of children acquiring HIV through mother-to-child transmission of HIV (MTCT) [7]. If the national targets of ensuring that at least $90 \%$ of all pregnant women have access to voluntary counseling and testing, $80 \%$ of all HIV-exposed infants have access to early infant diagnosis services, $80 \%$ of all HIV-positive pregnant women and HIV-exposed infants have access to efficacious ARV's and $80 \%$ of HIV-positive pregnant women have access to infant feeding counseling are to be met by 2015 [9], then it is essential to identify the socio-cultural factors that facilitate or hinder PMTCT service uptake in Nigeria.

The findings from the literature reviewed demonstrate that socio-cultural factors matter with PMTCT service uptake in Nigeria. Three main conclusions can be drawn from the literature reviewed. First, there are perceptions, ranging from positive to negative that influence PMTCT service uptake in Nigeria. While we observed a highlevel of acceptance for HIV testing and willingness to undertake voluntary counseling and testing, there continues to be negative perceptions, such as the fear of stigma and discrimination that influenced decisions and actions towards PMTCT service uptake such as HIV testing [47]. This finding is consistent with scholarly assertions which suggest that stigma and discrimination are major deterrents to voluntary counseling and testing for HIV [71]. For example, studies conducted in other parts of Africa highlighted the negative effects of HIV stigma and discrimination and suggested that it impedes efforts to promote voluntary counseling and testing as well as the provision of treatment, care and support $[16,71]$. In Nigeria, perceptions of stigma and the fear regarding spread of sero-positive status also influenced non-disclosure of HIV sero-positive status [31] and nonadherence to ARV's among HIV positive pregnant women [33]. If mother-to-child-transmission of HIV is to be effectively reduced in Nigeria, there is a continued need to examine the broader socio-cultural contexts in which stigma and discrimination occurs so as to develop effective culture-centered interventions focused on reducing stigma in PMTCT programs. Furthermore, routinely offering HIV tests to all pregnant women and their partners and integrating HIV testing with other prenatal tests and into other services will help further reduce the stigma and discrimination associated with HIV-only test approach.

A second, main conclusion that can be drawn from the literature is the role of enablers (resources) relative 
to societal or systemic factors in facilitating or hindering efforts to participate effectively in PMTCT programs. Positive enablers such as assurance of confidentiality results influenced willingness to test for HIV. Furthermore, health education programs were linked to acceptability of PMTCT programs, and participation in community support programs significantly influenced infant feeding choices. Negative enablers such as inadequate and inaccessible VCT, structural constraints at health centers including long distance to clinic and long waiting lines, coupled with financial difficulties and perceptions of stigma and discrimination greatly reduced uptake of PMTCT programs in Nigeria. The success of PMTCT efforts in Nigeria, particularly with reducing missed opportunities will rely on identifying culturally compelling ways to promote the positive enabling factors while changing the negative ones. Furthermore, findings from the literature indicated that efforts should be made to effectively integrate traditional birth attendants with prenatal, child delivery and postnatal care in Nigeria. Indeed, studies conducted elsewhere suggested that traditional birth attendants are critical with reducing missed opportunities for PMTCT particularly as their services are utilized by pregnant women not currently receiving formal antenatal care and they provide assistance during delivery and postpartum care [72,73]. Since up to $60 \%$ of pregnant mothers rely on the services of traditional birth attendants [20,32], recognizing their cultural and practical contribution is crucial for the success of PMTCT efforts in Nigeria.

The third conclusion drawn from the literature reviewed suggests that family contexts matter with decisions and actions towards PMTCT in Nigeria. Indeed family systems demonstrated remarkable capacities to adjust to the burden of HIV by readily providing support for family members living with HIV particularly following disclosure of sero-positive status [67]. The support provided by family members also influenced adherence to ARV's among pregnant women and infant feeding choice. In addition, the desire to procreate, an existential perception shared by many of HIV positive men and women in the literature reviewed was influenced by the strong cultural attachment placed on having children particularly with ensuring lineage continuity and posterity. Nonetheless, while there were positive and existential nurturing factors that influenced decisions and actions towards PMTCT service uptake, we also identified negative factors that hinder service uptake. These factors such as non-disclosure of seropositive status to significant others were influenced by perceptions of fear, stigma and discrimination. Failure to disclose also influenced non-adherence to ARV's and hindered PMTCT completion. Nevertheless, in cases where HIV positive women disclosed, partner testing for HIV was low. This is similar to findings reported in other parts of sub-Saharan Africa [74]. As a result, better culturally appropriate strategies are needed to effectively involve men in PMTCT efforts in Nigeria.

One strategy is to develop family-oriented, sustainable community-based programs that offer PMTCT services including voluntary counseling and testing services outside clinic settings. For example, congregation-based PMTCT programs such as the Healthy Beginning Initiative (HBI) in Southeast Nigeria [1] could serve as a model in that it utilizes the church network to decentralize testing beyond health facilities while improving access to testing and treatment services. A congregation-based approach to PMTCT in Nigeria is ideal for several reasons. First, faith plays an important role in the life of Nigerians. Ranked \#1 among 53 other nations in church attendance at $89 \%$, Nigeria has extensive penetration with faith-based institutions and faith plays a significant role in the social life of Nigerians $[1,75]$. The ubiquity of religious institutions in Nigeria and the growing involvement of faith-based organizations in HIV prevention present a unique opportunity to employ, and evaluate the effect of congregation-based approaches on HIV testing among pregnant women, male partners of pregnant women and PMTCT completion rate among $\mathrm{HIV}$-infected pregnant women [1]. A congregation-based approach holds great potential and has been used effectively in health promotion and disease prevention in communities where religion plays a prominent role [76-79]. This strategy may also be useful with reducing missed opportunities for PMTCT including perceptions of stigma and/or family pressure to engage in infant feeding methods. Moreover, this approach could easily be scaled up in any congregation setting and could serve as a model for other interventions aimed at improving maternal-child health outcomes [1].

\section{Conclusion}

\section{Limitations}

There are several limitations worth noting. First the generalizability of our findings is limited to PMTCT efforts within the Nigerian context. Second, our findings should be interpreted cautiously in the light of the sources of the data, variability in the methodologies used to collect data and even the use of the PEN-3 cultural model. Indeed, because most of the studies reviewed employed a cross-sectional design, causality among variables cannot be assumed. Also, since we limited our synthesis of the literature to only peer-reviewed literature in electronic databases, reliance on these sources prevents us from reaching decisive conclusions on the sociocultural factors influencing PMTCT efforts in Nigeria. However, our use of a theoretical model, the PEN-3 cultural model enabled us to ascertain the cultural factors influencing PMTCT service uptake, including what 
factors are beneficial and should be encouraged and what factors harmful and should be discouraged. Challenges associated with using the PEN-3 cultural model are also well documented [80] and they include transferability, that is the extent to which the findings from our synthesis of the literature can be transferred from one context to another.

Notwithstanding these limitations, this paper contributes to an emerging body of research demonstrating the importance of socio-cultural factors in influencing PMTCT service uptake in Nigeria. To our knowledge, this paper also represents the first use of a well-known cultural model to assess how these sociocultural factors influence PMTCT in Nigeria. If scaling up access to effective PMTCT services and virtual elimination of new HIV infection among children is to be achieved by 2015 , then socio-cultural factors that influence HIV testing, HIV disclosure, infant feeding choices or adherence to ARV's must be recognized as important with reducing pediatric HIV infections in Nigeria. Furthermore, the pervasive burden of MTCT in Nigeria presents a serious public health problem requiring multiple strategies to virtually eliminate HIV among children by 2015. One such strategy is to use widely available, socially acceptable infrastructure (religious institutions) in addition to healthcare facilities as they provide access to pregnant women close to their home environment. While improvements in the accelerated provision of comprehensive PMTCT services would in all likelihood make substantial contributions to reducing the transmission of HIV through MTCT, culture-centered, congregation-based PMTCT interventions focused on the range of the perceptions people have, the enabling factors that facilitate or hinder service uptake and the role of family and/or community contexts can also reduce MTCT.

\section{Conclusions}

Our review of the literature provide evidence to suggest that appropriate implementation of sound family-oriented, culture-centered interventions could go a long way towards achieving the comprehensive four pronged strategy currently in place in Nigeria, including: the primary prevention of HIV infection among women of reproductive age, the prevention of unintended pregnancies among HIV positive women, the prevention of HIV transmission from HIV infected mothers to their infants, and the provision of care and support for HIV infected mothers, infants and family members. Overall, the findings of the literature reviewed are congruent with the notion that culture matters with determining the level of health of the individual, family, and community context. Our findings also lend support to the idea that culture-centered interventions focused on the factors that nurture the individual including family contexts is crucial to the success of PMTCT service uptake such as HIV testing, infant feeding choices, and adherence to ARV's. Finally, while we examine the role of culture in this paper and are also making the case for faith-based intervention research, very little is known about the intersection of culture and faith particularly in the context of families. We believe this is an important area of future research.

\begin{abstract}
Abbreviations
HBI: Healthy Beginning Initiative; PEN-3 cultural model: Person, Extended Family, Neighborhood (Cultural Identity domain): Perceptions, Enablers, and Nurturers (Relationship and Expectation domain): Positive, Existential and Negative (Cultural Empowerment domain); PMTCT: Prevention of mother-tochild transmission of HIV.
\end{abstract}

\section{Competing interests}

The authors declare that they have no competing interests.

\section{Authors' contributions}

$\mathrm{JI}$ and EE conceived of and designed the study and drafted the manuscript. $\mathrm{CO}$ participated in the design of study and manuscript preparation. $\mathrm{MO}$ and CE participated in design and coordination of the study findings and manuscript preparation; GO participated in study design and draft of manuscript. All authors read and approved the final manuscript.

\section{Acknowledgement}

This publication is partially supported by the Eunice Kennedy Shriver National Institute of Child Health \& Human Development (NICHD), National Institute of Mental Health (NIMH) of the National Institutes of Health and PEPFAR under award number R01HD075050. The funding agency played no role in the study conception or design, writing of the manuscript, and decision to submit the manuscript for publication.

\section{Author details}

${ }^{1}$ Department of Kinesiology and Community Health, University of Illinois, Urbana-Champaign, 123 Huff Hall, 1206 S. Fourth St, Champaign, IL 61820, USA. ${ }^{2}$ Department of Pediatrics, University of Nevada School of Medicine, 2040 West Charleston Boulevard, Las Vegas, NV, USA. ${ }^{3}$ Department of Biobehavioral Health, The Pennsylvania State University, 219 Biobehavioral Health Building, University Park, PA 16802, USA. Prevention, Education, Treatment, Training and Research-Global Solutions-PeTR-GS, 7 Link Road, Independence Layout Enugu, Enugu 400001, Enugu State, Nigeria. ${ }^{5}$ Sunrise Foundation, Plot 358 New GRA, Enugu, Nigeria. ${ }^{6}$ Center for Healthful Behavior Change, Division of General Internal Medicine, Department of Medicine, New York University School of Medicine, New York, USA.

Received: 21 October 2013 Accepted: 17 July 2014

Published: 30 July 2014

\section{References}

1. Ezeanolue EE, Obiefune MC, Yang W, Obaro SK, Ezeanolue CO, Ogedegbe GG: Comparative effectiveness of congregation-versus clinic-based approach to prevention of mother-to-child HIV transmission: study protocol for a cluster randomized controlled trial. Implement Sci 2013, 8(1):62.

2. Nkwo P: Prevention of mother to child transmission of Human Immunodeficiency Virus: The Nigerian perspective. Annals of Medical and Health sciences Research 2013, 2(1):56-65.

3. NACA: National Agency for the Control of AIDS; Factsheet 2011, Update on the HIV/AIDS Epidemic and Response in Nigeria. Abuja, Nigeria; 2011.

4. UNAIDS: 2013 progress report on the Global Plan towards the elimination of new HIV infections among children by 2015 and keeping their mothers alive. Geneva; 2013.

5. NACA: National Agency for the Control of AIDS; Nigeria Global AIDS Response, County Progress Report. Abuja, Nigeria: 2012.

6. WHO: The World Health Organizations Global HIV/AIDS response. Geneva: World Health Organization; 2011.

7. UNAIDS: UBRAF 2012-2015 Country Case Study: Nigeria. Geneva: UNAIDS; 2011. 
8. WHO: PMTCT strategic vision 2010-2015: preventing mother-to-child transmission of HIV to reach the UNGASS and Millennium Development Goals. Geneva: World Health Organization; 2010.

9. NACA: National Agency for the Control of AIDS; Fact Sheet-PMTCT in Nigeria Abuja, Nigeria; 2011.

10. Airhihenbuwa CO, Webster JD: Culture and African contexts of HIV/AIDS prevention, care and support. SAHARA-J: Journal of Social Aspects of HIV/AIDS 2004, 1(1):4-13.

11. Airhihenbuwa CO: Healing our differences: The crisis of global health and the politics of identity. Lanham, Maryland: Rowman \& Littlefield; 2007.

12. Erwin DO, Treviño M, Saad-Harfouche FG, Rodriguez EM, Gage E, Jandorf L: Contextualizing diversity and culture within cancer control interventions for Latinas: Changing interventions, not cultures. Soc Sci Med 2010, 71(4):693-701.

13. Scarinci IC, Bandura L, Hidalgo B, Cherrington A: Development of a theory-based (PEN-3 and health belief model), culturally relevant intervention on cervical cancer prevention among Latina immigrants using intervention mapping. Health Promot Pract 2012, 13(1):29-40.

14. Cowdery JE, Parker S, Thompson A: Application of the PEN-3 model in a diabetes prevention intervention. Journal of Health Disparities Research and Practice 2012, 4(1):3.

15. Yick AG, Oomen-Early J: Using the PEN-3 model to plan culturally competent domestic violence intervention and prevention services in Chinese American and immigrant communities. Health Educ 2009, 109(2):125-139.

16. Airhihenbuwa C, Okoror T, Shefer T, Brown D, Iwelunmor J, Smith E, Adam $M$, Simbayi L, Zungu N, Dlakulu R: Stigma, culture, and HIV and AIDS in the Western Cape, South Africa: An application of the PEN-3 cultural model for community-based research. Journal of Black Psychology 2009, 35(4):407-432.

17. Betancourt TS, Abrams EJ, McBain R, Fawzi MC: Family-centred approaches to the prevention of mother to child transmission of HIV. J Int AIDS SoC 2010, 13(Suppl 2):S2

18. Kmet LM, Lee RC, Cook LS: Standard quality assessment criteria for evaluating primary research papers from a variety of fields. Edmonton: Alberta Heritage Foundation for Medical Research; 2004.

19. Nwakwuo GC, Oshonwoh FE: Assessment of the level of male involvement in safe motherhood in Southern Nigeria. J Community Health 2013, 38(2):349-356.

20. Ogbolu Y, Iwu E, Zhu S, Johnson J: Translating Research into Practice in Low-Resource Countries: Progress in Prevention of Maternal to Child Transmission of HIV in Nigeria. Nursing Research and Practice 2013, 2013:848567.

21. Olugbenga-Bello A, Adebimpe W, Osundina F, Abdulsalam S: Perception on prevention of mother-to-child-transmission (PMTCT) of HIV among women of reproductive age group in Osogbo. Southwestern Nigeria. International Journal of Women's Health 2013, 5:399.

22. Amoran OE, Salami OF, Oluwole FA: A comparative analysis of teenagers and older pregnant women in the utilization of prevention of mother to child transmission [PMTCT] services in, Western Nigeria. BMC International Health and Human Rights 2012, 12(1):13.

23. Hembah-Hilekaan SK, Swende TZ, Bito TT: Knowledge, attitudes and barriers towards prevention of mother-to-child transmission of HIV among women attending antenatal clinics in Uyam District of Zaki-Biam in Benue State, Nigeria: original research article. Afr J Reprod Health 2012, 16(3):27-34.

24. Nwabueze S, Adogu P, Adinma E, Ifeadike C, Nnebue C, llika A, Ikechebelu J: Determinants of subjective health status of HIV positive mothers in NAUTH Nnewi. Nigerian Journal of Medicine: Journal of the National Association of Resident Doctors of Nigeria 2012, 21(4):381.

25. Ogbe A, Mutihir J: Pattern of Contraception among HIV Positive Women in Jos University Teaching Hospital. Niger J Med 2012, 21(1):11-15.

26. Sofolahan $Y$, Airhihenbuwa C: Childbearing decision making: A qualitative study of women living with HIV/AIDS in Southwest Nigeria. AIDS Research and Treatment 2012, 1:4.

27. Ugwu G, lyoke C, Nwagbo D: The impact of health education on the awareness and acceptability of strategies for preventing mother to child transmission of HIV in Enugu, Nigeria. Nigerian Journal of Medicine: Journal of the National Association of Resident Doctors of Nigeria 2012, 21(4):441.

28. Bello F, Ogunbode O, Adesina O, Olayemi O, Awonuga O, Adewole I: Acceptability of counselling and testing for HIV infection in women in labour at the University College Hospital, Ibadan, Nigeria. Afr Health Sci 2011, 11(1):30-35.

29. Ezegwui $H$, Isiekwene $C$ : Sexual behaviour of pregnant mothers living with HIV/AIDS in Enugu, Nigeria. Nigerian Journal of Medicine: Journal of the National Association of Resident Doctors of Nigeria 2011, 20(4):432

30. Ezeanochie MC, Olagbuji BN, Ande AB, Kubeyinje WE, Okonofua FE: Prevalence and correlates of intimate partner violence against HIV-seropositive pregnant women in a Nigerian population. Acta Obstet Gynecol Scand 2011, 90(5):535-539.

31. Olagbuji B, Ezeanochie M, Agholor K, Olagbuji Y, Ande A, Okonofua F: Spousal disclosure of HIV serostatus among women attending antenatal care in urban Nigeria. Journal of Obstetrics \& Gynaecology 2011 , 31(6):486-488

32. Balogun $\mathrm{M}$, Odeyemi $\mathrm{K}$ : Knowledge and practice of prevention of mother-to-child transmission of HIV among traditional birth attendants in Lagos State, Nigeria. Pan African Medical Journal 2010, 5(7).

33. Enwereji $\mathrm{EE}$, Enwereji $\mathrm{KO}$ : Assessing factors that affect childbirth choices of people living positively with HIV/AIDS in Abia state of Nigeria. Oman Medical Journal 2010, 25(2):91.

34. Oladokun R, Awolude O, Brown B, Adesina O, Oladokun A, Roberts A, Odaibo G, Osinusi K, Olaleye D, Adewole I: Service uptake and performance of the prevention of mother-to-child transmission (PMTCT) programme in Ibadan, Nigeria. Afr J Med Med Sci 2010, 39(2):81-87.

35. Oladokun RE, Brown BJ, Osinusi K: Infant-feeding pattern of HIV-positive women in a prevention of mother-to-child transmission (PMTCT) programme. AIDS Care 2010, 22(9):1108-1114.

36. Adeleke S, Mukhtar-Yola M, Gwarzo G: Awareness and knowledge of mother-to-child transmission of HIV among mothers attending the pediatric HIV clinic Kano Nigeria. Ann Afr Med 2009, 8(4):210-214.

37. Brown B, Oladokun $R$, Osinusi $K$ : Situation analysis of the existing infant feeding pattern at the commencement of the prevention of mother to child transmission (PMTCT) of HIV programme in Ibadan. Niger J Clin Pract 2009, 12(4):421-428.

38. Ezechi O, Gab-Okafor C, Onwujekwe D, Adu R, Amadi E, Herbertson E: Intimate partner violence and correlates in pregnant HIV positive Nigerians. Arch Gynecol Obstet 2009, 280(5):745-752.

39. Ezegwui H, Nwogu-lkojo E, Enwereji J, Dim C: HIV serostatus disclosure pattern among pregnant women in Enugu, Nigeria. J Biosoc Sci 2009, 41(6):789.

40. Maru S, Datong , Selleng D, Mang E, Inyang B, Ajene A, Guyit R, Charurat M, Abimiku A: Social determinants of mixed feeding behavior among HIV-infected mothers in Jos, Nigeria. AIDS Care 2009, 21(9):1114-1123.

41. Moses A, Chama C, Udo S, Omotora B: Knowledge, attitude and practice of ante-natal attendees toward prevention of mother to child transmission (PMTCT) of HIV infection in a tertiary health facility, Northeast-Nigeria. East Afr J Public Health 2009, 6(2):128-135.

42. Mukhtar-Yola M, Gwarzo G, Galadanci H, Tukur J, Farouk Z, Adeleke S: HIV exposed infants: a preliminary report of the Aminu Kano Teaching Hospital experience. Niger Postgrad Med J 2009, 16(2):143-148.

43. Omuemu V Akemokwe F, Ahanmisi I: Attitude and practice of antenatal HIV screening among pregnant women attending a secondary health facility in Benin-city. Niger J Clin Pract 2008, 11(4):324.

44. Onah H, Ibeziako N, Nkwo P, Obi S, Nwankwo T: Voluntary counselling and testing (VCT) uptake, nevirapine use and infant feeding options at the University of Nigeria Teaching Hospital. Journal of Obstetrics and Gynaecology: the Journal of the Institute of Obstetrics and Gynaecology 2008 28(3):276-279

45. Sadoh W, Sadoh A, Adeniran K, Abhulimhen-lyoha B: Infant-feeding practices among HIV-infected mothers in an HIV-treatment programme. $J$ Health Popul Nutr 2008, 26(4):463-467.

46. Arulogun OS, Adewole IF, Olayinka-Alli L, Adesina AO: Community Gate Keepers' Awareness and Perception of Prevention of Mother-to-Child Transmission of HIV Services in Ibadan, Nigeria. Afr J Reprod Health 2007, 11(1):67-75

47. Okonkwo KC, Reich K, Alabi Al, Umeike N, Nachman SA: An Evaluation of Awareness: Attitudes and beliefs of pregnant Nigerian women toward voluntary counseling and testing for HIV. AIDS Patient Care STDS 2007, 21(4):252-260

48. Adeneye A, Brieger W, Mafe M, Adeneye A, Salami K, Titiloye M, Adewole T, Agomo P: Willingness to seek HIV testing and counseling among 
pregnant women attending antenatal clinics in Ogun State, Nigeria. Int Q Community Health Educ 2006, 26(4):337-353.

49. Daniel O, Oladapo O: Acceptability of prenatal HIV screening at the primary care level in Nigeria. Journal of Obstetrics and Gynaecology: the Journal of the Institute of Obstetrics and Gynaecology 2006, 26(3):191-194.

50. Ekabua J, Oyo-Ita A, Ogaji D, Omuemu V: KAP of HIV prevention and screening among pregnant women attending specialist antenatal clinics in Calabar, Nigeria. Nigerian Journal of Medicine: Journal of the National Association of Resident Doctors of Nigeria 2006, 15(4):409.

51. Sagay A, Musa J, Ekwempu C, Imade G, Babalola A, Daniyan G, Malu N, Idoko J, Kanki P: Partner disclosure of HIV status among HIV positive mothers in Northern Nigeria. Afr J Med Med Sci 2006, 35:119-123.

52. Sagay A, Onakewhor J, Galadanci H, Emuveyan E: HIV status of partners of HIV positive pregnant women in different regions of Nigeria: matters arising. Afr J Med Med Sci 2006, 35:125.

53. Igwegbe A, llika A: Knowledge and perceptions of HIV/AIDS and mother to child transmission among antenatal mothers at Nnamdi Azikiwe University Teaching hospital, Nnewi. Niger J Clin Pract 2005, 8(2):97-101.

54. Niyasu Z, Kabir M, Galadanci H, Abubakar I, Aliyu M: Awareness and attitude of antenatal clients towards HIV voluntary counselling and testing in Aminu Kano Teaching Hospital Kano Nigeria. Niger J Med 2005, 14(1):27-32

55. Oladapo O, Daniel O, Odusoga O, Ayoola-Sotubo O: Fertility desires and intentions of HIV-positive patients at a suburban specialist center. J Nat Med Assoc 2005, 97(12):1672-1681.

56. Chama C, Audu B, Kyari O: Prevention of mother-to-child transmission of HIV at Maiduguri, Nigeria. Journal of Obstetrics \& Gynecology 2004, 24(3):266-269.

57. Ekanem E, Gbadegesin A: Voluntary Counselling and Testing (VCT) for Human Immunodeficiency Virus: A study on acceptability by Nigerian women attending antenatal clinics. Afr J Reprod Health 2004, 8(2):91-100.

58. Fasubaa O, Ezechi O, Orji E, Olowookere O: Antenatal HIV screening in South West Nigeria: the client's perspective. Journal of Obstetrics and Gynaecology: the Journal of the Institute of Obstetrics and Gynaecology 2001, 21(1):24-26.

59. Orji E, Sotiloye D, Fawole A, Huyinbo K: Attitude of Abeokuta pregnant women to routine human immunodeficiency virus screening. Nigerian journal of medicine: journal of the National Association of Resident Doctors of Nigeria 2001, 10(4):173.

60. Owolabi A, Owolabi S: Socio-economic implications of the management of HIV positive pregnant women-a review of four cases in lle-lfe, Nigeria. Nigerian journal of medicine: journal of the National Association of Resident Doctors of Nigeria 2001, 10(4):169.

61. Erhabor O, Akani Cl, Eyindah CE: Reproductive health options among HIV-infected persons in the low-income Niger Delta of Nigeria. HIV/AIDS (Auckland, NZ) 2012, 4:29.

62. Smith DJ, Mbakwem BC: Antiretroviral therapy and reproductive life projects: mitigating the stigma of AIDS in Nigeria. Soc Sci Med 2010, 71(2):345-352.

63. Ekama S, Herbertson E, Addeh E, Gab-Okafor C, Onwujekwe D, Tayo F, Ezechi O: Pattern and determinants of antiretroviral drug adherence among Nigerian pregnant women. Journal of Pregnancy 2012, :851810.

64. Nwabueze AS, Adogu P, llika A, Uchefuna N, Ikechebelu J: Knowledge, attitude, beliefs and perception of HIV-positive women towards PMTCT program services in NAUTH Nnewi, Nigeria. Orient Journal of Medicine 2011, 23(1-4):30-37.

65. Adejuyigbe E, Orji E, Onayade A, Makinde N, Anyabolu H: Infant feeding intentions and practices of HIV-positive mothers in southwestern Nigeria. J Hum Lact 2008, 24(3):303-310.

66. Mukhtar-Yola M, Adeleke S, Gwarzo D, Ladan ZF: Preliminary investigation of adherence to antiretroviral therapy among children in Aminu Kano Teaching Hospital, Nigeria. African Journal of AIDS Research 2006, 5(2):141-144.

67. Iwelunmor J, Airhihenbuwa C, Okoror T, Brown D, BeLue R: Family systems and HIV/AIDS in South Africa. Int Q Community Health Educ 2006. 27(4):321-335.

68. Igwegbe A, Ugboaja J: Rate and correlates of HIV serostatus disclosure among HIV positive pregnant women in Nnewi southeastern Nigeria. Journal of Medicine and Medical Science 2010, 1(7):296-301.
69. Igwegbe A, Ugboaja J, Nwajiaku L: Prevalence and determinants of non-adherence to antiretroviral therapy among HIV-positive pregnant women in Nnewi, Nigeria. International Journal of Medicine and Medical Sciences 2010, 2(8):238-245.

70. Anoje C, Aiyenigba B, Suzuki C, Badru T, Akpoigbe K, Odo M, Odafe S, Adedokun O, Torpey K, Chabikuli ON: Reducing mother-to-child transmission of HIV: findings from an early infant diagnosis program in south-south region of Nigeria. BMC Public Health 2012, 12(1):184

71. Kalichman SC, Simbayi LC: HIV testing attitudes, AIDS stigma, and voluntary HIV counselling and testing in a black township in Cape Town, South Africa. Sex Transm Infect 2003, 79(6):442-447.

72. Peltzer K, Phaswana-Mafuya N, Treger L: Use of traditional and complementary health practices in prenatal, delivery and postnatal care in the context of HIV transmission from mother to child (PMTCT) in the Eastern Cape, South Africa. Afr J Tradit Complement Altern Med 2009, 6(2):155

73. Perez F, Aung KD, Ndoro T, Engelsmann B, Dabis F: Participation of traditional birth attendants in prevention of mother-to-child transmission of HIV services in two rural districts in Zimbabwe: a feasibility study. BMC Public Health 2008, 8(1):401.

74. Msuya S, Mbizvo E, Hussain A, Uriyo J, Sam N, Stray-Pedersen B: Low male partner participation in antenatal HIV counselling and testing in northern Tanzania: implications for preventive programs. AIDS Care 2008, 20(6):700-709.

75. University of Michigan: Percentage of adult population that attends Church at least once a week. 1997 [Accessed online at http://ns.umich. edu/Releases/1997/Dec97/chr121097a.html on July, 2013]

76. Campbell MK, Hudson MA, Resnicow K, Blakeney N, Paxton A, Baskin M: Church-based health promotion interventions: evidence and lessons learned. Annu Rev Public Health 2007, 28:213-234.

77. Abanilla PKA, Huang K-Y, Shinners D, Levy A, Ayernor K, Aikins A-G Ogedegbe O: Cardiovascular disease prevention in Ghana: feasibility of a faith-based organizational approach. Bull World Health Organ 2011, 89(9):648-656.

78. DeHaven MJ, Hunter IB, Wilder L, Walton JW, Berry J: Health programs in faith-based organizations: are they effective? Am J Public Health 2004, 94(6):1030-1036.

79. Drake BF, Shelton R, Gilligan T, Allen JD: A church-based intervention to promote informed decision-making for prostate cancer screening among African-American men. J Natl Med Assoc 2010, 102(3):164.

80. Iwelunmor J, Newsome V, Airhihenbuwa CO: Framing the impact of culture on health: a systematic review of the PEN-3 cultural model and its application in public health research and interventions. Ethn Health 2014, 19(1):20-46.

doi:10.1186/1471-2458-14-771

Cite this article as: Iwelunmor et al:: Socio-cultural factors influencing the prevention of mother-to-child transmission of HIV in Nigeria: a synthesis of the literature. BMC Public Health 2014 14:771.

\section{Submit your next manuscript to BioMed Central and take full advantage of:}

- Convenient online submission

- Thorough peer review

- No space constraints or color figure charges

- Immediate publication on acceptance

- Inclusion in PubMed, CAS, Scopus and Google Scholar

- Research which is freely available for redistribution

Submit your manuscript at www.biomedcentral.com/submit
C) Biomed Central 